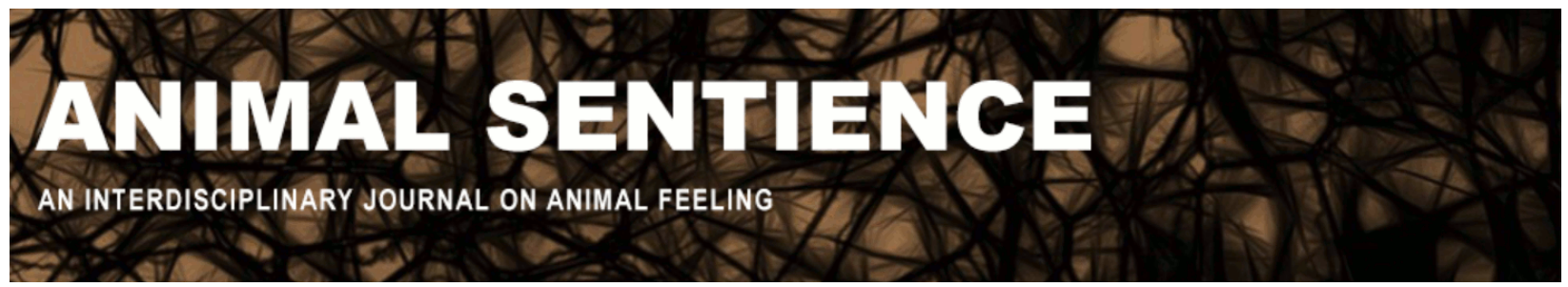

Porcher, Ila France (2019) The perfecting of the octopus. Animal Sentience 26(15)

DOI: $10.51291 / 2377-7478.1494$

Date of submission: 2019-06-22

Date of acceptance: 2019-07-02

(c) (†)

This article has appeared in the journal Animal

Sentience, a peer-reviewed journal on animal

cognition and feeling. It has been made open access,

free for all, by WellBeing International and deposited

in the WBI Studies Repository. For more information,

please contact

wbisr-info@wellbeingintl.org.

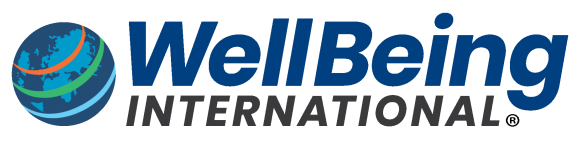

SOLUTIONS FOR PEOPLE, ANIMALS AND ENVIRONMENT 


\title{
The perfecting of the octopus
}

Commentary on Mather on Octopus Mind

\author{
Ila France Porcher \\ Independent Ethologist
}

\begin{abstract}
Cephalopods split away from the phylogenetic tree about half a billion years ago, and octopus evolution has been accelerated by an extremely low survival rate. This helps explain why this unusual animal presents qualities found in no other. It has a radially organized nervous system with a processing centre for each of its eight tentacles. Yet, although this might suggest that each tentacle has its own centre of consciousness, it remains just one animal, with one mouth to feed, and one life to lose, and it behaves as if it is centrally controlled. Its capacity for a range of intelligent and often cognitive behaviour suggests that it must have its own version of sentience.
\end{abstract}

Ila France Porcher is an ethologist who began writing books about the behaviour and intelligence of sharks when the population of several hundreds she had been studying, through underwater observation, was massacred for shark fin soup. She is the author of The Shark Sessions, The True Nature of Sharks, and Merlin: The Mind of a Sea Turtle. Website

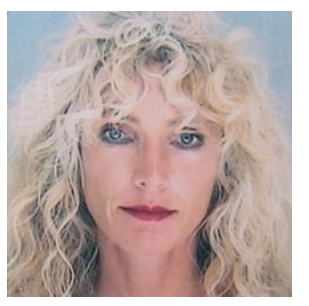

Commenting from the perspective of elasmobranchology, the first notable point is that cephalopods, like sharks, split off the phylogenetic tree approximately half a billion years ago, and evolved into creatures very different from their closest "relatives." Like sharks, they survived extinction events that eliminated most species and that provided new niches into which they could evolve. Thus, as with the shark, evolution has perfected the octopus. Part of its inheritance is a large brain and a highly complex radially organized neural system (Mather 2019).

Unlike sharks, however, cephalopods were prey, not predators. Their survival rate of less than 0.1 to $2 \%$ indicates that octopus evolution has been sped up exponentially. Consider the astronomical odds that across some 1 to 3 billion generations, each ancestor of an octopus living today survived to reproduce. Traits unseen anywhere else in the animal kingdom have evolved in the octopus; it is scarcely conceivable that a member of homo sapiens could ever understand one. The unorganized way the octopus walks, and approaches other situations, for example, may be the result of unpredictability having been selected for, hundreds of millions of times. Trut (1999) provides a canid example of how few generations selection requires to produce significant changes in inherited features.

A high fraction of the octopus's body-mass consists of its tentacles. With eight of them, each laden with suckers filled with sense organs, it is not surprising that $3 / 5$ of the animal's nervous system is involved in their function. The evolution of a separate processing centre for each arm doubtless had survival value, considering the multi-tasking by the central brain that 
would otherwise be required, and how vital reaction time is to survival. Carls-Diamante's (2017) idea that octopus consciousness may not be unified is speculative. No matter how an octopus's experience feels to it, an octopus has just one life to lose and behaves as if it is one animal. It has been shown that the central brain is in control (Gutnick et al. 2011). Furthermore, the nerve centres in the tentacles are interconnected and linked straight to the central brain; they are not isolated.

Nor do I find findings on human split-brain patients relevant to the experience of a dynamic and highly successful wild octopus. Healthy humans use different parts of their brains for different actions and feel different while doing so yet they are always the same person; and can focus their attention onto the sensations from a small part of their body, such as their tongue, or just one fingertip. Different brain regions have evolved to take over different functions in different classes of animals (Kotrschal et al. 1998; Glynn 1999; Marino 2002), further diluting any comparison of the octopus with homo sapiens. The octopus's ability to display contrasting skin colours on opposite sides of their body could reflect light direction rather than brain lateralization. The ability could have been selected for in the way the octopus's other very extensive capacities to fool observers have evolved. The test of octopus subjectivity has been its evolutionary success, and for that it must have been able to comprehend reality accurately enough to respond to it appropriately.

Mather has documented a variety of cognitive abilities in the octopus. They are also capable of social learning; they can learn the solution to a test by watching another animal (Fiorito \& Scotto 1992). In a surprising test suggesting self-awareness, a wild-caught octopus will check the size of a cage opening with a tentacle or two prior to using it for escape. If the hole is too small, it will not make the effort (Discovery documentary 2017).

Each time I have seen an octopus, it was doing something more capable than the vertebrates around it. An octopus carrying half a coconut shell was preparing for a possible threat in the future when it set off that day. It held in mind a mental representation of the shell's purpose (for hiding) and what circumstances would trigger its use. Another, carrying armloads of sand from its hole and tossing them down the bank, was also behaving intentionally.

Mather discusses the octopuses' capacity to play as a possible indication of consciousness. One night, a small octopus began shooting through my light beam. Zooming along with its tentacles streaming behind, its shape was so fish-like that it took a moment to recognize. I stopped and it settled on the sand, its mantle spread around it. I walked my hand toward it, and it wrapped its tentacles around my forearm briefly, its light touches like those of a playful kitten. For a long time, we played this game of chase, and the octopus repeatedly encircled my hands with light, brief touches. Perhaps play is a more common part of the octopus nature when free than when caged.

Occasionally an octopus approached my shark gathering to take a piece of food. One individual drew near very slowly, looking like an outcropping covered with seaweed. Such a feat requires an overseeing awareness controlling all of the tentacles, the skin colour and texture, and the motion, in an intentional action with the goal of getting a piece of food from under the noses of several sharks. It is questionable how such complex behavior - assuming a future in the making and demonstrating learning from the past - could be generated by an unconscious life-form. It seems reasonable to allow that there is an "I," a self-serving awareness or 
consciousness controlling the manipulation of the mental concepts, making moment-tomoment decisions about the proceedings, and keeping its goals in mind as it pursues its life.

The paramecium, a single-celled animal, has been shown to present a complex variety of preferences indicating learning and memory (Armus et al. 2006). Other studies have demonstrated that plants show the ability to learn and remember (Gagliano 2014), and amoebas and slime moulds have abilities that were thought to depend on brain circuitry (Reid et al. 2012). These findings indicate how little we know about thought and consciousness, and that they exist in life forms very different from the human and its brain.

The refusal to deal with evidence that some animals' actions reveal thinking was not addressed until Griffin (1992) wrote Animal Minds. Many articles in Animal Sentience have identified a continuing political bias against recognizing animal sentience, especially in animals with commercial value (e.g., Sneddon et al. 2018; Marino \& Merskin 2019).

It would be interesting to learn how sentience-deniers explain the way this delectable creature and all of its ancestors could have learned to avoid becoming someone's dinner so many billions of times and in so many ways if its environment did not make sense to it. If the human mind cannot access some other reality, does that mean it does not exist? Things that cannot be imagined by humans, because they are not found on the surface of this planet, comprise the vast majority of the universe. As long as the basis of sentience remains unknown to science, no conclusions denying it to animals can be drawn.

\section{References}

Armus, H. L., Montgomery, A. R., \& Gurney, R. L. (2006) Discrimination learning and extinction in paramecia (P. caudatum). Psychological Reports, 98(3), 705-711.

Carls-Diamante, S. (2017) The octopus and the unity of consciousness. Biological Philosophy, 32, 1269-1287.

Discovery documentary. (2017) Aliens of the deep sea.

Fiorito, G., \& Scotto, P. (1992) Observational learning in Octopus vulgaris. Science, 256(5056), 545-547.

Gagliano, M., Renton, M., Depczynski, M., \& Mancuso, S. (2014) Experience teaches plants to learn faster and forget slower in environments where it matters. Oecologia, 175(1), 63-72.

Glynn, I. (1999) An anatomy of thought: The origin and machinery of the mind. Wiedenfield and Nicholson, London.

Griffin, D. R. (1992, 2001) Animal minds. University of Chicago Press, Chicago.

Gutnick, T., Byrne, R. A., Hochner, B., \& Kuba, M. (2011) Octopus vulgaris uses visual information to determine the location of its arm. Current Biology, 21, 460-462.

Kotrschal, K., Van Staaden, M., \& Huber, R. (1998) Fish brains: Evolution and environmental relationships. Reviews in Fish Biology and Fisheries, 8, 373.

Marino, L. (2002) Convergence of complex cognitive abilities in cetaceans and primates. Brain, Behaviour and Evolution, 59, 21-32.

Marino, L., \& Merskin, D. (2019) Intelligence, complexity, and individuality in sheep. Animal Sentience 25(1).

Mather, J. (2019) What is in an octopus's mind? Animal Sentience 26(1). 
Reid, C. R., Latty T., Dussutour A., \& Beekman, M. (2012) Slime mold uses an externalized spatial "memory" to navigate in complex environments. PNAS, 109(43), 17490-17494.

Sneddon, L. U., Lopez-Luna, J., Wolfenden, D. C. C., Leach, M. C., Valentim, A. M., Steenbergen, P. J., Bardine, N., Currie, A. D., Broom, D. M., \& Brown, C. (2018) Fish sentience denial: Muddying the waters. Animal Sentience 21(1).

Trut, L. (1999). Early canid domestication: The farm-fox experiment. American Scientist, 87(2), 160-169. 